Tissue Engineering in Oral and Maxillofacial Surgery : From Lab to Clinics

\title{
Seppänen-Kaijansinkko, Riitta
}

Springer

2018

Seppänen-Kaijansinkko , R \& Mannerström , B 2018 , Tissue Engineering in Oral and Maxillofacial Surgery : From Lab to Clinics . in J H Meurman (ed.), Translational Oral Health Research . Springer , pp. 103-122 . https://doi.org/10.1007/978-3-319-78205-8_9

http://hdl.handle.net/10138/327286

https://doi.org/10.1007/978-3-319-78205-8_9

unspecified

acceptedVersion

Downloaded from Helda, University of Helsinki institutional repository.

This is an electronic reprint of the original article.

This reprint may differ from the original in pagination and typographic detail.

Please cite the original version. 
Chapter 10

Tissue engineering in oral and maxillofacial surgery

- from lab to clinics.

\author{
Riitta Seppänen-Kaijansinkko \\ Bettina Mannerström
}

Oral and Maxillofacial Diseases

University of Helsinki and Helsinki University Hospital

riitta.seppanen-kaijansinkko@helsinki.fi (corresponding author)

tel: +358294127285

Bettina.mannerstrom@helsinki.fi

tel: +358294127288 
Tissue engineering has been considered as a third treatment modality complementing medicine and surgery. It was first defined in 1993 by Langer and Vacanti (1993). Today it is a rapidly growing field of research expanding to all disciplines in medicine. Currently, it is possible to engineer both hard and soft tissues in oral and maxillofacial surgery.

Tissue engineering consists usually of three components: scaffolds, cells and regulating factors. Scaffolds are preferably biodegradable, i.e. they resorb when they are no longer needed while regenerated tissue fills the space of resorbed material. Different types of cells can be used depending on the type of required tissue. Both stem cells as well as differentiated cells have been used while regulating factors are most often growth factors. The growth of vascularization, to enable adequate delivery of nutrients and oxygen, must also be taken into account when constructs are of large size and diffusion is not enough to keep the construct vital. Regulating factors can be proteins, such as growth factors, culture media ingredients and structural or physical elements. The required tissue can be manufactured either in the body, on the site of the defect or ectopically, for example in muscular environment from where it is transplanted later, when mature enough, to the defect site. In this chapter, the past and the present of tissue engineering in oral and maxillofacial surgery will be elaborated, not forgetting the future perspectives.

\section{Keywords}

Oral surgery

Maxillofacial surgery

Tissue engineering

Regenerative medicine

Stem cells

Cells

Scaffold materials

Extracellular vesicles

3D printing 


\section{Background}

Regenerative medicine aims at the functional restoration of tissue malfunction, damage or loss, and can be divided into three main approaches. Firstly, the cell-based therapies, where cells are administered to re-establish a tissue either directly or through paracrine functions. Secondly, the often referred to as classical tissue engineering, consisting of the combined use of cells and a biodegradable scaffold to form tissue. Thirdly, there are material-based approaches, which have made significant advances which rely on biodegradable materials, often functionalized with cellular functions (De Jong et al. 2014).

In 1993, Langer and Vacanti, determined tissue engineering as an "interdisciplinary field that applies the principles of engineering and the life sciences toward the development of biological substitutes that restore, maintain, or improve tissue function". They published this definition in Science in 1993.

Tissue engineering has been classically thought to consist of three elements: supporting scaffold, cells and regulating factors such as growth factors (Fig. 1). Depending on the tissue to be regenerated, all three vary. Currently, it is known, that many other factors may have an effect on the outcome of the regenerate. These include factors enabling angiogenesis, physical stimulation, culture media, gene delivery and methods to deliver patient specific implants (PSI) (Fig. 2). During the past two decades, major obstacles have been tackled and tissue engineering is currently being used clinically in some applications while in others it is just taking its first baby steps.

\section{Materials}

Materials in tissue engineering can be manufactured with different techniques. The most common ones are molding and 3D printing. Scaffolds can also be porous granules inserted into a hollow container or biodegradable mesh, which provides the shape and size of the construct. The scaffold acts as extracellular matrix, which later is resorbed and replaced by proper extracellular matrix synthetized by cells. 


\section{Used materials}

A large variety of materials have been introduced to aid tissue engineering both in soft and hard tissues. They can be used as scaffolds to keep the cells and growth factors in the desired area or only to give size and shape to the construct (a mesh filled with the scaffold material).

In soft tissue engineering, collagen and freeze-dried cadaveric human dermis are currently most used material as scaffolds in oral and maxillofacial surgery (Kim et al 2017). They will resorb in due time leaving the cells to replace the missing tissue. In some applications, it is important to use a laminated scaffold to enable the growth of a 3D-structure with different tissue types.

In bone tissue engineering, the most commonly used materials are biodegradable granules of betatricalcium phosphate (ß-TCP), hydroxyapatite (HA) and bioactive glass (BAG) (Mesimäki et al 2009, Dayashankar et al 2017, Stoor et al 2017a, Stoor et al 2017b, Kowal et al 2017). The mesh is usually made out of titanium or bioresorbable materials such as polylactic acid (PLA) or its composites. The scaffold materials as well as the bioresorbable mesh will degrade and the space is filled with newly formed bone. The speed of degradation depends on the used materials. The mesh is often shaped manually or with indirect printing, where a template of the defect (and required reconstruction) is manufactured and the mesh shaped to surround it. It can also be manufactured with the aid of direct 3D printing.

\section{D printing}

With 3D printing, it is possible to produce custom made scaffolds and mesh for tissue engineering. By using of computer aided design and manufacturing (CAD-CAM), the scaffolds will be very precise and accurate. As facial structures are quite complex, this has brought huge advantages to managing different materials. Most used techniques are inkjet printing, laser-assisted printing, extrusion printing and stereolithography. All these require top-class imaging and manipulation the data as well as fine algorithms. CAD-CAM in medicine consists of four consecutive phases: (1) CT 3D imaging data; (2) data conversion, CAD; (3) planning of surgery/manufacturing of implant; and (4) actual surgery accordingly (Seppänen-Kaijansinkko and Kontio 2017). After the scaffold has been manufactured, it is possible to seed the scaffold by cells and add growth factors, if needed.

\section{Cells}

In tissue engineering, both differentiated primary cells as well as stem cells can be used as a source. 
Primary cells are cells taken from living tissue. They have undergone only a few divisions and, hence, represent the cells in the original tissue extremely well. The main obstacle when using these cells is the limited number that can be obtained.

\section{Stem cells}

Stem cells are cells which can make perfect copies of themselves (self-renewal) or differentiate to specialized cell types. Several cell types are gathered under the same umbrella called 'stem cells; 1) human embryonic stem cells (hESCs), 2) human induced pluripotent stem cells (hiPSCs), which are in fact reprogrammed somatic cells, and 3) adult stem cells, which cover several types of cells of hematopoietic and mesenchymal origin. Mesenchymal stem cells (MSCs) and tissue-specific progenitors reside in the human body in most tissues throughout an individual's life and generally have a limited expansion and differentiation.

Pluripotent stem cells can differentiate to all specialized cell types. The main source is the inner cell mass of human embryo (hESC) but lately hiPSCs have gained a lot of interest in clinical cell therapy and regenerative medicine (Fig 3). When making iPSC lines, somatic cells are genetically reprogrammed using transcription factors (Takahashi et al. 2007, Yu et al. 2007). When using both hESCs and hiPSCs there is a risk of mutations already in the laboratory, due to the lengthy in vitro culturing time and extensive cell manipulation (International Stem Cell Initiative 2011). In vivo reports of tumorigenicity have raised concern for safe in using these cells in clinical work (Csobonyeiova et al. 2015).

Some of the most promising research in regenerative medicine is focusing on the use and applicability of stem cells. The main stem cells used in tissue engineering are tissue derived, so called adult stem cells, which can be extracted from most adult tissues. They can be transplanted back to the same individual (autologous transplantation) avoiding risks of disease transfer or immunological reactions. They can also be transplanted to another individual (allogenic transplantation) (Rosenbaum et al. 2008).

Mesenchymal stem cells (MSCs) are of great interest to both clinicians and researchers, due to their great potential in tissue engineering. Their ease of isolation and manipulation, and potential for differentiation are qualities that have gathered interest. Despite their frequent use in research, detailed standardized criteria are called for as to the identification of these cells from their various locations, as they are not all the same; the International Society for Cellular Therapy has published a set of guidelines attempting to standardize the expansion of these cells but more standardization is still needed (Horwitz et al. 2005, Dominici et al. 2006, Krampera et al. 2013). 
The most commonly studied MSCs are derived from bone marrow (bone marrow stem/stromal cells; BM-MSC) and adipose tissue (adipose tissue stem/stromal cells; AT-MSCs). While both BMMSCs and AT-MSCs have an approximately equal potential to differentiate into cells and tissues of mesodermal origins (i.e., adipocytes, cartilage), AT-MSCs have a distinct advantage: they are more readily accessible than BM-MSCs. While comparative analysis of the two subtypes of MSCs has shown that there is no difference in regard to morphology, immune phenotype, isolation success and colony frequency, differences do arise in regard to osteogenic and chondrogenic differentiation, with AT-MSCs exhibiting smaller potential for osteogenesis and chondrogenesis than BM-MSCs (Rosenbaum et al. 2008) (Figs 4 and 5).

MSCs are currently the focus of clinical and scientific research due to their exceptional abilities for their immunomodulatory properties. However, MSCs cannot be considered truly hypoimmunogenic; rejection of allogeneic MSC immunosuppressive potential and immunogenicity are influenced by levels of systemic or local inflammatory cytokines. High immunosuppressive potential simply allows MSCs to suppress inflammation and delay allogeneic rejection through suppression more efficiently than other allogeneic cell types. Many believe that the therapeutic effect of MSCs is due to a 'hit-and-run' mechanism mediated by the production of extracellular vesicles (EVs) or exosomes or secretion of trophic and immunomodulatory factors. Nevertheless, a comprehensive understanding of MSC mechanism of action in cell therapy is still under investigation and many questions remain to be answered (Ankrum et al. 2014).

Adult stem cell-based therapies are already clinically available, additionally, more than 3,000 trials associated with stem cells are currently registered in the World Health Organization International Clinical Trials Registry Platform (http://apps.who.int/trialsearch/). The majority of these are adult stem cell-based therapies, but the registry also includes the first pluripotent-based (hESC/hiPSC) clinical trials, associated with eye diseases such as macular dystrophy or degeneration. Albeit that the technology is in place to produce a wider range of therapies, especially safety issues are not completely understood, subsequently there is a cautious transition from bench to bedside and application of technologies. (Ankrum et al. 2014)

\section{Bioprinting}

The cells can also be printed together with certain biomaterials combined with growth factors, if needed. The first bioprinting technique was inkjet printing, which is fast and cost-effective. The resolution is high but the quality of vertical structure is poor. Cell density is also low. It has been used to engineer blood vessels, bone, cartilage and neurons. (Tuan et al. 2003) 
When using laser-assisted printing, the cost is high while cell viability is excellent (>95\%). The resolution is high and the vertical structure quality is fair. This technique has been used in blood vessel, bone, skink and fat regeneration. The high cost has prevented this technique becoming very common. The printers are mostly complex and cumbersome compared to other types of printers. All in all, this technique is still immature for clinical work. (Mandrucky et al. 2017, Keriquel et al. 2017)

Stereolithography is also relatively cheap and fast. The resolution is high and the quality of vertical structure is good with good cell density and cell viability (>85\%). It has been used in blood vessel and cartilage engineering. (Gou et al 2014, Mandrucky et al. 2015)

Bioprinting by extrusion, which is modified inkjet printing, can be used when biomaterial is very viscous. It is of moderate cost but slow. Cell viability is also moderate (40-80\%), resolution moderate but vertical structure is of good quality with high cell density. Currently, most commonly used bioprinters are based on extrusion technology. (Mandrycky et al. 2015)

\section{Growth factors}

Bone morphogenetic factors (BMPs) play a central role in bone and cartilage development, as well as in adult homeostasis of bone metabolism, but also ow known to play crucial roles in all organ systems. Therefore, it has even been suggested that BMPs should be named body morphogenetic proteins (Reddi 2005). Currently, the BMP family is comprised of several members from BMP-2 to BMP-18.

Though BMPs were initially discovered to induce bone formation, BMP-3 for instance has been shown to be a negative regulator of bone density. Some BMPs may have redundant roles in bone formation, as conditional deletion of BMP-7 from limb has no noticeable effect (Wang et al 2014). Further, the osteogenic potential of BMPs have reported contradictory results in in vitro studies. In two- and three-dimensional cultures of AT-MSCs, supplementation of BMP-6, BMP-7 and vascular endothelial growth factor (VEGF) and their combinations showed no significant enhancement of the osteogenic differentiation (Kyllönen et al. 2013), while others reported a synergistic effect of BMP-6 and VEGF on the osteogenic differentiation of the same cells (Li et al. 2015). In a study using periodontal ligament cells, supplementation with BMP-2 or BMP-6 showed no enhanced osteogenesis (Khanna-Jain et al. 2011)

BMP-2 is best studied in the context of osteogenesis and has been indicated to have potential in bone formation, however, the reports have been contradictory both in vitro and in vivo. 
Nevertheless, studies suggest that source of serum supplementation of the in vitro cultures may play a role, with human serum supplemented media showing accelerated biochemical responsiveness to BMP-2 compared with fetal bovine serum (FBS) in AT-MSC cultures (Vanhatupa et al. 2015). Further, the species origin in which the growth factor is produced is of the also important for its response, with BMP-2 of mammalian origin showing enhanced response in vitro compared with BMP-2 of bacterial origin (Vanhatupa et al. 2015). These results may give one explanation to the existing contradiction in the reported BMP- 2 studies on AT-MSCs in vitro.

Due to their approval for clinical use, BMP-2 and -7 are probably the most studied growth factors for bone tissue engineering. However, the translation of BMP-2 and -7 to clinical use has been hindered by various problems, including high administration dosage, safety issues, short half-life and high cost relative to efficacy (Garrison et al. 2007). The safe administration dosage may be one the reason to the complications and safety issues concerning BMP-2 in off-label use in the cervical spine to increase bone growth and bony fusion. The FDA published a safety communication on recombinant human BMP-2 use in 2015, especially for pediatric patients, with recommendation to cautiousness in the use of BMPs until further safety evidence is available.

\section{Enhancing osteogenesis using physical stimulation}

Bone is a tissue capable of modifying its structure and mass according to the mechanical loading it is exposed to. This process occurs through the intrinsic balance in the mechanosensitive activation of the osteoblasts and the osteoclasts (Palomares et al. 2009).

Several of studies have provided robust evidence that reduced mechanical loading results in decreased bone mass, and that increased mechanical loading can be utilized to enhance bone formation in vivo as well as in clinical cases. Further, animal and human studies have led to the examination of mechanical loading in cell models. Studies have shown, that bone cells and their pre-cursors and also MSCs exhibit mechanosensitivity in vitro in response to various mechanical stimuli, however, there is no consensus on the most effective combination of vibration loading parameters for osteoinduction (Kyllönen et al. 2011).

Further, osteogenesis can be enhanced in vitro using another potential strategy, by application of conductive polymers as a functional surface coating on biomaterial scaffolds. One of the conductive polymers (CPs), polypyrrole (PPy), has shown great promise in tissue engineering, not only because it can mediate electrical currents, but also because it may enhance the bioactivity of biomaterials in bone applications. Reports show, that AT-MSCs cultured on polymer scaffolds coated with PPy 
induced with electric stimulation supported the viability and proliferation of the AT-MSCs as well as supported osteogenesis (Pelto et al. 2013, Sayyar et al. 2016).

\section{Experimental studies}

In preclinical studies, regeneration of many tissues in the oral and maxillofacial have been studied. Of these, teeth, salivary glands and nerves have not yet been explored in clinical applications.

\section{Teeth}

Considering teeth, many different types of cells are needed, including dental pulp regeneration, dentino- and amelogenesis (Dissanayka and Chang 2017, Wang et al. 2017, Hu et al. 2017). In the future, it might be possible to regenerate the root of a tooth, but at the moment it seems impossible to guide the shape and color of the crown of a tooth. Hence, dental regeneration at least at the moments, cannot replace dental implants.

\section{Periodontal ligament}

Infection leading to loss of periodontal ligament is very common in adults and the treatment methods need improving (Hu et al. 2017). In long term cultures, surprisingly, estrogen seems to have properties to retain the stemness of periodontal ligament stem cells (Ou et al., in press). New materials such as zein (protein derived from corn) can be electrospun with gelatin and seems to support the growth of periodontal ligaments cells. This, however, is not yet in clinical use (Yang et al. 2017).

\section{Salivary glands}

Salivary gland regeneration has been studied quite extensively, however, no clinical studies have been reported yet. Salivary hypofunction can be caused by systemic diseases such as Sjögren's syndrome, but it may also be due to radiotherapy in the head and neck region. Secretion of saliva is extremely important for the well-being of oral mucosa and teeth, however, no adequate saliva substitutes to replace the hypofunction of the glands has been developed. For tissue-engineered salivary gland, it is necessary also to be able to connect the secretion of saliva to the complex ductal system to deliver the saliva to oral cavity. However, function of salivary glands including secretion of bioactive molecules in case of radiotherapy might be feasible when using AT-MSCs administrated by systemic routes, i.e. blood stream, by paracrine mechanisms which will provide 
growth factors helping neovascularization and promoting epithelial proliferation as well as angiogenesis (Tabatabaei and Sheykhhasan 2017). Dental follicle -derived stem cells have been shown to be able to differentiate to salivary gland and duct cells, which might be a promising future treatment modality (Xu et al. 2017).

\section{Cartilage}

In cartilage tissue engineering, committed chondrocytes, ESCs and MSCs have been used. Based on the results and availability of cells, MSCs seem to be a viable choice for this application. The regenerated cartilage in the joint will have to bear large contact area strains and stresses. It must also allow growth of functional tissue by providing appropriate cell-scaffold interactions (Seo and $\mathrm{Na} 2011)$.

To enable long term survival of cells inside the scaffold, the scaffold must be either porous or woven. These properties will challenge the appropriate strength of the scaffold. In oral and maxillofacial surgery, the need for cartilage is usually in the temporomandibular joint (TMJ). Mäenpää with her coworkers (2010) studied the regeneration of TMJ discs in rabbits. The bilayer scaffold disc comprised of a non-woven mat of resorbable PLA and a PLA membrane plate. ATMSCs were seeded in the discs and cultured in parallel in control and chondrogenic medium for six weeks. Relative expression of the genes, aggrecan, type I collagen and type II collagen, normally present in the TMJ disc extracellular matrix, increased in the discs in the chondrogenic medium. They concluded that the PLA discs seeded with AT-MSCs have potential in the development of a tissue-engineered TMJ disc. The same group later used these discs in in ten rabbit TMJs. The original TMJ disc was bilaterally removed and the AT-MSC-seeded PLA disc was used to replace the removed original disc on one side. On the other side the cell-seeded PLA disc was pretreated in chondrogenic differentiation media. Unfortunately, the cone beam computed tomography and histology showed, that most of the discs had dislocated and caused sclerotic changes and condylar hypertrophy in the joints. The pretreated discs seemed to function slightly better than the nonpretreated discs. No signs of foreign body reaction, infection or inflammation could be seen. The authors conclude that better disc design and fixation technique might lead to better results (Ahtiainen et al. 2013).

To be able to regenerate mandibular condyle, it must be realized that both the bone and the cartilage must be produced and bound together. Chondrocytes and osteoblasts can be harvested or differentiated from above mentioned many sources: The properties of the scaffold needed is different for bone and for cartilage. The growth factors used need to differ as well. However, if this 
could be safely and predictably performed, this approach would give great relief to patients suffering from major TMJ disorders and diseases. (Wang and Detamore 2007)

Nasal cartilage has also been a target for tissue engineering. Chang et al. (2007) used autologous chondrocytes injected in fibrin glue to rabbits' dorsal nasal bones. The histological result was identical to that of normal auricular cartilage. The concentration of fibrinogen and thrombin as well as chondrocytes play a crucial role in the formation of the cartilage. If cartilage cells are not available, bone marrow as well as umbilical cord derived stem cells have been studied. The umbilical cord derived cells seemed to produce more type I collagen and aggregan compared to bone marrow derived cells, a finding which warrants further studies also in a sandwich-type construct for osteochondral reconstruction (Wang et al. 2009, Wang et al. 2011).

\section{Clinical work}

There are two main objectives in maxillofacial reconstruction: surgery should provide form and function of oromaxillofacial area. As facial skeleton has a very complex structure, and reconstruction should restore volume, shape, bone continuity and symmetry of bone skeleton. On the other hand, soft and hard tissues in this area enable several functions like articulation, mimics, mastication, swallowing and breathing. When the reconstruction is carried out, esthetic and reconstructive aims need to be met.

Clinically, the applications have been mainly in bone regeneration as well as in epithelial defect repair. Currently, the aim is also to avoid all animal-derived materials and replace them with synthetic or human-derived materials, such as recombinant human BMP (rhBMP) and human serum.

\section{Soft tissue regeneration}

Currently, surgeons often use collagen sponges and freeze-dried cadaveric human dermis to replace missing soft tissue (Kim et al. 2017). However, tissue-engineered approaches have also been introduced and they will be elucidated below.

\section{Oral Mucosa}

Oral mucosal grafts have also been used in clinical work. EVPOME ${ }^{\circledR}$, a tissue engineered ex vivoproduced full thickness mucosal graft, has shown the ability to create keratinized mucosal surface 
epithelium when grafted on an intact periosteal bed. EVPOME ${ }^{\circledR}$ is manufactured in the laboratory from the patient's own keratinocytes (from biopsies of the palate) seeded and cultured on an acellular dermal matrix. It has proven to be safe and have potential to augment keratinized mucosa around teeth. (Izumi et al. 2013)

\section{Lips}

On top of esthetics, lips provide several other functions. These include eating (closure of the oral cavity), breathing (by nose), articulation and sensation (hot, cold, etc.). They also play an important role in facial expressions.

Regeneration of lips is very difficult especially when there is a large defect which cannot be repaired with local flaps. To regenerate an avulsed lip, both the surface structures (underlying muscles and surface structures such as skin and mucosa) have to be considered. (Duisit et al. 2017) For tissue-engineered construct to be successful, it needs adequate blood supply to enable survival of cells. A sufficient fixation of different tissues plays also a crucial role in the healing and regeneration process.

\section{Skin}

Already approximately one million patients, mainly burn patients and patients with diabetic ulcers, have received tissue engineered human skin. Dermagraft ${ }^{\circledR}$ (PGA + neonatal fibroblasts) was one of the first commercially available products for skin defects (Langer \& Vacanti 2016). Currently, allogenic skin grafts are available as off-the-shelf products. However, they are somewhat immunogenic and may transfer diseases, although the risk is minimal after extensive testing required for these products. Skin grafts can be manufactured to replace only epidermis or dermis of both. Unfortunately, hair follicles or sweat glands are not yet included in these grafts.

\section{Hard tissue regeneration}

\section{Cartilage}

Our own research group has used tissue engineering to produce cartilage to the nasal septum. The two operations, in which a resorbable Chronos ${ }^{\circledR}$ sheet was seeded with patients' own ASCs, were successful. However, one of the patients continued her nose picking with artificial nails and after the initial healing period the graft was lost. (Sandor et al. 2014). 
Bone

Bone transplants are the second most used tissues in clinical work after blood transfusions (Shegarfi and Reikeras 2009). However, if autologous bone is used, usually another surgical site required which causes more morbidity to the patient as well as extends the length of the operation. Bone banks provide solution for this is some cases as allogeneic bone can quite safely be used even though there is a small risk of immunologic reactions and disease transfer. Bone grafts usually resorb partly, hence, in oral and maxillofacial area it might in some cases be difficult to predict how much bone needs to be transplanted.

\section{Sinus lift}

Sinus lift is one of the most common procedures to enable placement of dental implants in the edentulous maxilla. Traditionally it is carried out by using autologous bone harvested in the craniomaxillofacial skeleton or iliac crest. However, it was one of the first application where bone regeneration was attempted by tissue engineering. The used carries for cells and/or growth factors are resorbable fleeces, HA, bovine bone and, naturally, autologous and allogenic bone.

Schimming \& Schmeltzheisen (2004) used periosteal cells on a resorbable (polyglactin 910 combined with polydioxanone) fleece in 27 patients for augmentation of edentulous posterior maxilla. They used Good Manufacturing Practice (GMP) -class expanded periosteal cells from mandibular angle and the fleece was soaked with cell suspension. Bovine thrombin in FBS was used to seal the cells in the fleece. Cells were cultured for nearly 2 months after which they were transplanted in the sinus floor. One patient had to be dropped out due to an infection. In 18 patients the result was excellent, however an unsuccessful result was seen in 8 patients (30\%) needing further supplementary autologous bone transplantation.

Meijer et al. (2008) augmented sinus floors or walls prior to dental implant insertion in six patients. BM-MSCc were harvested from iliac crest and cultured for a week on porous HA in an osteogenic culture medium, containing also xenogeneic materials such as FBS. The cells were then transplanted and the augmentation effect studied 4 months after augmentation. Of the 11 biopsies taken, bone formation was observed only in 3 patients (50\%). It can be speculated, that inadequate vascular supply might have been the reason for failures.

\section{Other small local defects}

In oral and maxillofacial surgery, large bone defects, caused by cysts, are often filled with autologous bone, bovine bone or synthetic materials such as hydroxyapatite (HA), B-TCP or BAG. In a study published by Stoor et al. (2017a) 21 bony cavities in 20 patients were filled with BAG 
S53P4, some even in the presence of infection (65\%). The authors state that the use of this material provides and infection-free and reliable bone regeneration. When cells have been used, autogenous osteoblasts seeded in biomaterials have shown to be an excellent choice to fill these defects compared to iliac crest bone grafts (Pradel et al. 2006). Unfortunately, the need for a GMP-class facility to produce the tissue engineered filling materials is very labor-intensive and not very cost effective hindering their use to become more widespread. According to current legislation, iliac crest bone graft can be obtained simultaneously during the same operation when the cyst is removed, hence lowering the costs markedly.

\section{Continuity defects}

Continuity defects are caused mainly due to tumor ablation of trauma. The can include only the bone, sometimes teeth and some soft tissue. If the soft tissue coverage and blood supply to it is adequate, it is possible to tissue-engineer the transplant directly in the defect site. However, if there is a major loss of soft tissue, the construct needs to be transplanted first to an ectopic site and after maturation transplanted again to the defect site either as a microvascular flap or a pedicled flap.

\section{On-site regeneration}

Zétola and his coworkers published a case report in 2010 of a repair of a mandibular defect repair after resection of an ameloblastoma using recombinant human morphogenetic protein-2 associated with collagen sponge, autogenous bone chips and synthetic HA and $\beta$-TCP blocks. No cells were transplanted. Titanium reconstruction plate and titanium scaffold filled the above-mentioned combination was implanted into defect area. Collagen with rhBMP-2 was superposed above open titanium mesh to allow muscle cells and periosteum to migrate to defect area. After 7 months, the patient had a stable occlusion. Control CT showed good bone formation directed to the center of the defect. The authors concluded that the reported reconstruction technique gave a satisfactory result with less invasive surgery and with minimum morbidity. However, studies with larger number of patients are required to indicate the treatment modality as a routine in cases of bone continuity defects.

In 2015, Park et al. reported a case study, where a large continuity defect after resection of ameloblastoma in the angle of the mandible was reconstructed with iliac bone and autologous BMMSCs. The iliac bone served as a scaffold, fixed with titanium plates and screws, with cancellous bone removed. The gap was then filled with cultured BM-MSCs and fibrin glue covered with collagen membranes. Later three dental implants were placed in the graft resulting in uneventful healing. 
Stoor et al. (2017b) used direct CAD - CAM technique and tissue engineering to repair mandibular defects in 14 patients immediately at the time of ablation surgery. Most of the patients had squamous cell carcinoma or ameloblastoma. The surgery was simulated and patient specific implant (PSI) designed on virtual model. The PSI was a combination of scaffold and reconstruction plate with screw holes. The scaffold was filled with $\beta$-TCP and autologous bone. In four patients with ameloblastoma or drug induced osteonecrosis cases BMP-2 soaked in a sponge was placed to cover the cage to improve the bone formation. Finally, PSI was covered with collagen membrane or sponge (10 patients) and either radial for arm or anterolateral thigh (ALT) microvascular flap (12 patients). The follow up was between $9-24$ months. The overall recovery of the patients was favorable considering how demanding the patients were. Nine patients had an uneventful recovery. The main reasons for failure were infection and dehiscence of the mucosa or the microvascular flap. In these cases, extreme caution should be exercised to avoid soft tissue injury or dehiscence during the surgery and follow up.

It is noteworthy, that all these reports can be estimated having been successful due to sufficient coverage of the regenerate with vascular soft tissue enabling oxygen and nutrient supply to the healing area.

\section{Ectopic prefabrication}

One of the first clinical papers was published by Warnke and coworkers in 2004. They reconstructed a mandibular continuity defect using vascularized custom-made bone flap with indirect technique in which patient's CT data was uploaded to CAD software and the defect reconstructed in the mandible was virtually simulated. A virtual implant to repair the defect was designed and converted into solid 3D Teflon replica, which was used as a model when manually shaping titanium mesh around it. The shaped mesh was filled with bovine bone mineral blocks combined with growth factor rhBMP-7, bovine collagen type-1 and autologous iliac crest bone marrow. The filled mesh was implanted into patient's back muscle (latissimus dorsi). A microvascular flap was raised 7 weeks later and 4 weeks after the implantation the patient was able to use her mandible and was satisfied with the aesthetic outcome. The authors concluded that ectopic bone formation is possible and causes less burden to the patient compared to conventional bone grafts.

Mesimäki et al. (2009) reconstructed a major hemimaxillary bone and soft tissue defect caused by removal of recurrent keratocyst in a middle-aged male patient. The patient was very unhappy with his removable obturator prosthesis. The construct consisted of $\beta$-TCP as scaffold material seeded with patient's autologous adipose-derived stem cells expanded in a GMP-class laboratory and 
commercially available growth factor BMP-2. The material was the inserted into a titanium mesh preformed to fit the size and shape of the defect. The construct was first implanted into the patient's rectus abdominis muscle, where it was let to mature for 8 months. After maturation, the construct together with the surrounding muscle was transplanted using microvascular technique (TRAM-flap) to the site of the defect and connected with titanium plates and screws to the adjacent bones. The anastomosis of flap recipient vessels was performed to neck vessels and flap was fixated with titanium plates. After uneventful healing, four dental implants were inserted into the regenerated bone and a fixed bridge was used to reconstruct the masticatory function. The histology obtained at the time of fixture operation confirmed normal bone tissue in heterotopic bone area. The follow-up has been uneventful for a decade, only some small pieces of titanium mesh have had to be removed as they have protruded through the thin oral mucosa (unpublished results). (Figs. 6-8)

The same group performed similar reconstruction to a male patient after total maxillary defect caused by ablation of a large squamous cell carcinoma (SCC). The combination of AT-MSCs, $\beta$ TCP granules, rhBMP-2 in polylactide scaffold was implanted into the ALT-flap and shaping of a resorbable polylactic scaffold was done with computer aided design, with indirect technique. Patient specific (PS) titanium reconstruction plates were used to fix the future 'neomaxilla'. After maturation of 7 months the microvascular ALT flap with heterotopic bone was raised and placed into area of resected maxilla. Dental implants were inserted after uneventful healing of 5 months. The prosthetic reconstruction was established with removable prosthesis (unpublished results). The largest number of patients with using autologous stem cells in 13 consecutive cases of craniomaxillofacial hard-tissue reconstruction has been published by Sandor et al. (2014). The reconstruction was carried out with expanded autologous hAT-MSCs, $\beta$-TCP and in most cases, BMP-2. The group reported on reconstruction of defects at four anatomically different sites: cranial bone (5), frontal sinus (3), mandible (3), and nasal septum (2). In the mandible, continuity defect repair was carried out using computer aided surgical planning and AT-MSCs. If scaffolds were needed, titanium mesh or $\beta$-TCP sheet was used. The patients were followed between up to 51 months. Two patients with mandibular reconstruction received a total number of seven dental implants later, which are being loaded in masticatory function. The authors concluded that although results are promising, further research is needed with animal studies and long-term human series. This view is supported by other research groups, too.

Matsuo et al. (2010) used indirect technique in mandible defect repair. After surgical simulation, a PLA PS mesh tray was manually prepared and filled with HA. Intraoperatively, particulate cancellous bone and marrow was harvested and with platelet-rich plasma (PRP) placed into the tray. Two patients with mandible defect was included to the study. The follow-up was 28 and 33 months. 
One of the patients received dental implants after 10 months of the initial surgery. The heterotopic bone was macroscopically well formed. The CT evaluation showed good bone quality and the screws used to attach the resorbable mesh tray did not hinder placement of dental implants. The neovascularization with prompt recovery of nutrition is considered to be a key issue of bone regeneration. Kokemueller and coworkers (2010) reported a clinical case of hemimandibular defect that was reconstructed with the combination of autologous iliac crest bone marrow, $\beta$-TCP and rhBMP-2 in titanium scaffold. The reason for the defect was chronic osteomyelitis. The patient suffered from several other comorbidities as well. They designed and produced $\beta$-TCP cylinder that had central passage with the diameter of $7 \mathrm{~mm}$. The for blood-soaked cylinders were implanted into latissimus dorsi muscle. Perforator vessels were placed into central passage to enhance capillary growth. After 6 months, the flap with heterotopic bone was raised and transferred to oral and maxillofacial (OMF) defect and covered with titanium mesh. The mesh was fixed with titanium screws. There was no complication during the follow up of 1 year. The authors conclude that the use of autologous bone marrow and $\beta$-TCP block with central vessels to repair OMF bone defects is reliable and well tolerated. Furthermore, most of the donor site morbidity can be avoided with this technique. The research group performed also experimental studies with same protocol and the results confirmed the clinical achievements.

\section{Regulatory aspects}

Tissue engineering and regenerative medicine is regulated by FDA in US and by EMA in Europe. The manipulated cells are considered as Advanced Therapy Medicinal Products (ATMP) and the regulation is very strict. The engineered tissues must be manufactured according to Current Good Manufacturing Practices (cGMP) standards, which includes a flawless quality control system including testing of raw materials, establishing a detailed standard operating procedures (SOPs), detecting any deviations of these procedures, detecting possible contaminations as well as maintaining reliable testing laboratories and follow-up systems.

\section{Products available in EU}

In Europe, only four products have received manufacturing license, namely Chrondrocelect ${ }^{\circledR}$, Zalmoxis ${ }^{\circledR}, \mathrm{MACI}{ }^{\circledR}$ and the only one using stem cells: Holoclar®. Of these, only two are available in the market at the moment. 
Chrondrocelect $\AA$ is a product where patient's own cartilage samples are surgically removed from "less important" parts of the cartilage and the extracted chondrocytes are expanded in a GMP-class lab. The expanded cells are the inserted surgically to the defect site. For unknown reason, the marketing authorization for Chondrocelect has been withdrawn at the request of the marketingauthorization holder in 2017.

MACI ${ }^{\circledR}$ is quite similar to Chrondrocelect ${ }^{\circledR}$, i.e. using patient's own chondrocytes expanded and seeded in a collagen matrix, which is transplanted to the defect site. At the moment, it is not available as the manufacturing site has not received an approval from EMA. If a new manufacturing site will be approved, MACI ${ }^{\circledR}$ could be available to the patients.

Zalmoxis ${ }^{\circledR}$ is used for patients as an add-on treatment in adults who have received a hematopoietic stem cell transplant due to leukemia or lymphoma from a partially matched donor. Before receiving the transplant, the patient's own cells from bone marrow have been removed, hence, predisposing the patient to infections. Zalmoxis ${ }^{\circledR}$ contains genetically altered T-cells which will help the patient in restoring his/her immune system. Zalmoxis ${ }^{\circledR}$ is an orphan medicine and has been granted manufacturing license in 2016.

Holoclar® is the first and only stem cell based ATMP product to enter the European market and received the manufacturing license at the end of 2014. It is aimed to help patients with a moderate or severe limbal cell deficiency in the eye, which can eventually cause blindness. Holoclar ${ }^{\circledR}$ is based on patients own limbal stem cells.

\section{Products manufactured in the operating room}

On the other hand, surgeons may combine cells, growth factors and materials in the operating room without any ATMP approvals as long as everything occurs during the same surgical procedure and the cells are used for homologous (i.e. same tissue type) reconstruction. The main obstacle causing high prices is the labor-intensive work carried out in GMP-class laboratories as well as the extensive preclinical and clinical trials required for manufacturing license. (Rubin et al. 2016)

\section{Future perspectives}

In order for tissue engineering and regenerative medicine to be feasible treatment methods, more detailed experimental studies as well as controlled clinical studies are needed. The manufacturing of these products is very expensive and often the end products are patient specific, preventing large scale manufacturing which could lead to cost-effectiveness. 
It is still unclear, whether cells or growth factors are needed if local neighboring cells can initiate healing or growth factors are abundant in the area. This might be the case with bone defect and locally preserved periosteum.

Growth factors and stem cells have been speculated to be a risk for malignant transformation. With mesenchymal stem cells this has not been proven. When using growth factors there still is a suspicion of hypertrophic growth and malignant transformation (O'Neill et al. 2016, Weiss 2015). Hence, they should not be used in patients with malignancies.

Currently there is a shift occurring in the field of regenerative medicine, with less of the focus on cell-based treatment options and more weight is put on strategies that allow functional restoration of damaged tissues by cell-free approaches. Recent insights suggest that the structural contribution of stem cells to regenerated tissues is limited, and that it is rather the stimulation of local healing processes plays an important role, research has increasingly focused on the paracrine hypothesis, exploring the factors released by the cells, including growth factors, cytokines, and EVs (for a review, see De Jong et al. 2014).

EVs are lipid membrane vesicles, containing a variety of RNA species, proteins, and potentially even DNA. EVs function in many processes, including cell-to-cell communication, immune modulation, angiogenesis, and cellular proliferation and differentiation. Cells release several types of vesicles with different physiological properties, and function (De Jong et al. 2014). Generally, the term EV is used when discussing exosomes or microvesicles, or a combination of these vesicle populations albeit conflicting definitions still exist (Gould et al. 2013). Extracellular vesicles are able to affect several cell processes in a paracrine manner. These paracrine effects of EVs have a potential benefit in regenerative medicine, as EVs can be incorporated in treatments for example by injection, mixing with hydrogels, or coating scaffolds with EV using fibrin gels or specific linkers. Subsequently, EV show great potential for a role in regenerative medicine. Given the supportive role of EV in tissue regeneration, further studies may lead to the discovery of novel regenerative therapeutics, as well as methods to improve current techniques.

Despite of all regulatory and other hurdles, every year more clinical trials end up successful and eventually will lead to clinical applications. Multidisciplinary collaboration plays a key role in this process - we need clinicians, scientists, engineers, regulatory experts and many more specialists to provide patients the best possible care. 


\section{References}

Ahtiainen K, Mauno J, Ellä V, Hagström J, Lindqvist C, Miettinen S, et al. Autologous adipose stem cells and polylactide discs in the replacement of the rabbit temporomandibular joint disc. J Royal Soc Interface. 2013 May 29;10(85):20130287. doi: 10.1098/rsif.2013.0287. [Epub 2013 Aug 6].

Ankrum JA, Ong JF, Karp JM. Mesenchymal stem cells: immune evasive, not immune privileged. Review. Nat Biotechnol. 2014 Mar;32(3):252-60. doi: 10.1038/nbt.2816. [Epub $2014 \mathrm{Feb} 23]$.

Chang J, Rasamny JJ, Park SS. Injectable tissue-engineered cartilage using a fibrin sealant. Arch Facial Plast Surg. 2007 May-Jun;9(3):161-6.

Csobonyeiova M, Polak S, Koller J, Danisovic L. Induced pluripotent stem cells and their implication for regenerative medicine. Review. Cell Tissue Bank. 2015 Jun;16(2):171-80. doi: 10.1007/s10561-014-9462-9. [Epub 2014 Jul 19].

Dayashankar CP, Deepika PC, Siddaramaiah B. Clinical and radiographic evaluation of citric acid-based nano HA composite graft in the regeneration of intrabony Defects - A randomized controlled trial. Contemp Clin Dent. 2017 Jul-Sep;8(3):380-386. doi: 10.4103/ccd.ccd_213_17.

De Jong OG, Van Balkom BW, Schiffelers RM, Bouten CV, Verhaar MC. Extracellular vesicles: potential roles in regenerative medicine. Review. Front Immunol. 2014 Dec 3;5:608. doi: 10.3389/fimmu.2014.00608. eCollection 2014.

Dissanayaka WL, Zhang C. The role of vasculature engineering in dental pulp regeneration. J Endod. 2017 Sep;43(9S):S102-S106. doi: 10.1016/j.joen.2017.09.003.

Dominici M, Le Blanc K, Mueller I, Slaper-Cortenbach I, Marini F, Krause D, et al. Minimal criteria for defining multipotent mesenchymal stromal cells. The International Society for Cellular Therapy position statement. Cytotherapy. 2006;8(4):315-7.

Duisit J, Maistriaux L, Taddeo A, Orlando G, Joris V, Coche E, et al. Bioengineering a human face graft: The matrix of identity. Ann Surg. 2017 Nov;266(5):754-764. doi: 10.1097/SLA.0000000000002396.

Garrison KR, Donell S, Ryder J, Shemilt I, Mugford M, Harvey I, Song F. Clinical effectiveness and cost-effectiveness of bone morphogenetic proteins in the non-healing of fractures and spinal fusion: a systematic review. Health Technol Assess. 2007 Aug;11(30):1-150, iii-iv. 
Gou M, Qu X, Zhu W, Xiang M, Yang J, Zhang K, et al. Bio-inspired detoxification using 3D-printed hydrogel nanocomposites. Nat Commun. 2014 May 8;5:3774. doi: 10.1038/ncomms4774.

Gould SJ, Raposo G. As we wait: coping with an imperfect nomenclature for extracellular vesicles As we wait: coping with an imperfect nomenclature for extracellular vesicles. $\mathbf{J}$ Extracell Vesicles. 2013; 2: 10.3402/jev.v2i0.20389. Published online 2013 Feb 15. doi: $10.3402 /$ jev.v2i0.20389

Heslop JA, Hammond TG, Santeramo I, Tort Piella A, Hopp I, Zhou J, et al. Concise review: workshop review: understanding and assessing the risks of stem cell-based therapies. Stem Cells Trans1 Med. 2015 Apr;4(4):389-400. doi: 10.5966/sctm.2014-0110. [Epub 2015 Feb 26]

Horwitz EM, Le Blanc K, Dominici M, Mueller I, Slaper-Cortenbach I, Marini FC, et al. Clarification of the nomenclature for MSC: The International Society for Cellular Therapy position statement. Cytotherapy. 2005;7(5):393-5.

Hu L, Liu Y, Wang S. Stem cell-based tooth and periodontal regeneration. Oral Dis. 2017 Jun 21. doi: 10.1111/odi.12703. [Epub ahead of print]. International Stem Cell Initiative. Screening ethnically diverse human embryonic stem cells identifies a chromosome 20 minimal amplicon conferring growth advantage. Nat Biotechnol. 2011 Nov 27;29(12):1132-44. doi: 10.1038/nbt.2051.

Izumi K, Neiva RF, Feinberg SE. Intraoral grafting of tissue-engineered human oral mucosa. Int J Oral Maxillofac Implants. 2013 Sep-Oct;28(5):e295-303. doi: 10.11607/jomi.te11.

Kestle JRW. Food and Drug Administration Safety Communication on rhBMP-2 use. Editorial. J Neurosurgery Pediatr. 2015 Jul;16(1):1-3. doi: 10.3171/2015.2.PEDS15112. [Epub 2015 Apr 10].

Keriquel V, Oliveira H, Rémy M, Ziane S, Delmond S, Rousseau B, et al. In situ printing of mesenchymal stromal cells, by laser-assisted bioprinting, for in vivo bone regeneration applications. Sci Rep. 2017 May 11;7(1):1778. doi: 10.1038/s41598-017-01914-x. Khanna-Jain R, Agata H, Vuorinen A, Sándor GKB, Suuronen R, Miettinen S. Addition of BMP-2 or BMP-6 to dexamethasone, ascorbic acid, and $\beta$-glycerophosphate may not enhance osteogenic differentiation of human periodontal ligament cells. Growth Factors. 2010 Dec;28(6): 437-46. DOI: 10.3109/08977194.2010.495719. [Epub 2010 Jun 23]. Kim RY, Bae SS, Feinberg SE. Soft Tissue Engineering. Oral Maxillofacial Surg Clin North Am. 2017 Feb;29(1):89-104. http://dx.doi.org/10.1016/j.coms.2016.08.007. 
Kokemueller H, Spalthoff S, Nolff M, Tavassol F, Essig H, Stuehmer C, et al. Prefabrication of vascularized bioartificial bone grafts in vivo for segmental mandibular reconstruction: experimental pilot study in sheep and first clinical application. Int J Oral Maxillofac Surg. 2010 Apr;39(4):379-87. doi: 10.1016/j.ijom.2010.01.010. [Epub 2010 Feb 18].

Kowal T, Hahn NC, Eider S, Marzillier J, Fodera DM, Thamma U, et al. New BAG scaffolds with exceptional qualities for bone tissue regeneration: Response of osteoblasts and osteoclasts. Biomed Mater. 2017 Oct 16. doi: 10.1088/1748-605X/aa9385. [Epub ahead of print]

Krampera M, Galipeau J, Shi Y, Tarte K, Sensebe L. MSC Committee of the International Society for Cellular Therapy (ISCT)Immunological characterization of multipotent mesenchymal stromal cells - The International Society for Cellular Therapy (ISCT) working proposal. Cytotherapy 2013 Sep;15(9):1054-61.

Kyllönen L, Haimi S, Säkkinen J, Kuokkanen H, Mannerström B, Sándor KB, et al. Exogenously added BMP-6, BMP-7 and VEGF may not enhance the osteogenic differentiation of human adipose stem cells. Growth Factors. 2013 Oct;31(5):141-53. doi: 10.3109/08977194.2013.817404. [Epub 2013 Jul 23].

Langer R, Vacanti JP. Tissue engineering. Science. 1993 May 14;260(5110):920-6. Review. Langer R, Vacanti J. Advances in tissue engineering. J Pediatr Surg. 2016 Jan 51(1):8-12 doi: 10.1016/j.jpedsurg.2015.10.022. [Epub 2015 Nov 10].

Li CJ, Madhu V, Balian G, Dighe AS, Cui Q. Cross-Talk Between VEGF and BMP6 Pathways Accelerates Osteogenic Differentiation of HumanAdipose-Derived Stem Cells. J Cell Physiol. 2015 Nov;230(11):2671-82. doi: 10.1002/jcp.24983.

Mandrycky C,Wang Z, Kim K, Kim DH. 3D bioprinting for engineering complex tissues. Biotech Adv. 2016;34: 422-34. doi: 10.1016/j.biotechadv.2015.12.011. [Epub 2015 Dec 23].

Matsuo A, Chiba H, Takahashi H, Toyoda J, Abukawa H. Clinical application of a custommade bioresorbable raw particulate HA/poly-L-lactide mesh tray for mandibular reconstruction. Odontology. 2010 Feb;98(1):85-8. doi: 10.1007/s10266-009-0111-x. [Epub 2010 Feb 16].

Meijer GJ, de Bruijn JD, Koole R, van Blitterswijk CA. Cell based bone tissue engineering in jaw defects. Biomaterials. 2008 Jul;29(21):3053-61. doi:

10.1016/j.biomaterials.2008.03.012. [Epub 2008 Apr 22].

Mesimäki K*, Lindroos B *, Törnwall J, Miettinen S, Mauno J, Lindqvist C, et al. *equal contribution. Novel maxillary reconstruction with ectopic bone formation by GMP adipose 
stem cells. Int J Oral Maxillofac Surg. 2009 Mar;38:201-9. doi: 10.1016/j.ijom.2009.01.001. [Epub 2009 Jan 24].

Mäenpää K, Ellä V, Mauno J, Kellomäki M, Suuronen R, Ylikomi T, et al. Use of adipose stem cells and polylactide discs for tissue engineering of the temporomandibular joint disc. $\mathbf{J}$ R Soc Interface. 2010 Jan 6;7(42):177-88. doi: 10.1098/rsif.2009.0117. [Epub 2009 May 27].

Ou Q, Wang X, Wang Y, Wang Y, Lin X. Oestrogen retains human periodontal ligament stem cells stemness in long-term culture. Cell Prolif. 2017 Oct 12. doi: 10.1111/cpr.12396. [Epub ahead of print].

O'Neill HL, Cassidy AP, Harris OB, Cassidy JW. BMP2/BMPR1A is linked to tumour progression in dedifferentiated liposarcomas. PeerJ. 2016 Apr 19;4:e1957. doi: 10.7717/peerj.1957. eCollection 2016.

Park JS, Kim BC, Kim BH, Lee JI, Lee J. Up-and-coming mandibular reconstruction technique with autologous human bone marrow stem cells and iliac bone graft in patients with large bony defect. J Craniofac Surg. 2015 Nov;26(8):e718-20. doi: 10.1097/SCS.0000000000002224.

Pelto J, Björninen M, Pälli A, Talvitie E, Hyttinen J, Mannerström B, Suuronen Seppanen R, Kellomäki M, Miettinen S, Haimi S. Novel polypyrrole-coated polylactide scaffolds enhance adipose stem cell proliferation and early osteogenic differentiation. Novel polypyrrole-coated polylactide scaffolds enhance adipose stem cell proliferation and early osteogenic differentiation. Tissue Eng Part A. 2013 Apr;19(7-8):882-92. doi: 10.1089/ten.TEA.2012.0111. [Epub 2013 Jan 4].

Pradel W, Eckelt U, Lauer G. Bone regeneration after enucleation of mandibular cysts: comparing autogenous grafts from tissue-engineered bone and iliac bone. Oral Surg Oral Med Oral Pathol Oral Radiol Endod. 2006 Mar;101(3):285-90. [Epub 2006 Jan 19] Reddi AH. BMPs: from bone morphogenetic proteins to body morphogenetic proteins. Cytokine Growth Factor Rev. 2005 Jun;16(3):249-50.

Rosenbaum AJ, Grande DA, Dines JS. The use of mesenchymal stem cells in tissue engineering. A global assessment. Organogenesis. 2008 Jan-Mar; 4(1): 23-27.

Rubin JP, Gurtner GC, Liu W, March KL, Seppanen-Kaijansinkko R, Yaszemski MJ, et al. Surgical Therapies and Tissue Engineering: At the Intersection Between Innovation and Regulation. Tissue Eng Part A. 2016 Mar;22(5-6):397-400. doi:

10.1089/ten.TEA.2016.0002. 
Salisbury Palomares KT, Gleason RE, Mason ZD, Cullinane DM, Einhorn TE, Gerstenfeld LC, et al. Mechanical stimulation alters tissue differentiation and molecular expression during bone healing. J Orthop Res. 2009 Sep; 27(9): 1123-32. doi: 10.1002/jor.20863. Sándor GK, Numminen J, Wolff J, Thesleff T, Miettinen A, Tuovinen VJ, et al. Adipose stem cells used to reconstruct 13 cases with cranio-maxillofacial hard-tissue defects. Stem Cells Transl Med. 2014 Apr;3(4):530-40, 2014. doi: 10.5966/sctm.2013-0173. [Epub 2014 Feb 20].

Sayyar S, Bjorninen M, Haimi S, Miettinen S, Gilmore K, Grijpma D, Wallace G. UV Cross-Linkable Graphene/Poly(trimethylene Carbonate) Composites for 3D Printing of Electrically Conductive Scaffolds. ACS Appl Mater Interfaces. 2016 Nov 23;8(46):3191631925. [Epub 2016 Nov 10].

Schimming R, Schmelzeisen R. Tissue-engineered bone for maxillary sinus augmentation. J Oral Maxillofac Surg. 2004 Jun;62(6):724-9.

Seo S, Na K. Mesenchymal stem cell based tissue engineering for chondrogenesis. A review. J Biomed Biotechnol. 2011;806891. doi: 10.1155/2011/806891. [Epub 2011 Oct 9]. Seppänen-Kaijansinkko R, Kontio R. Tissue engineered maxillofacial reconstruction: Focus on bone. In: Kuriakose, MA, editor. Contemporary Oral Oncology. Vol 3. Springer International Publishing; 2017. p. 343-56. DOI 10.1007/978-3-319-43854-2_16.

Shegarfi H, Reikeras O. Review article: bone transplantation and immune response. J Orthop Surg (Hong Kong) 2009 Aug;17:206-11. DOI: 10.1177/230949900901700218. Stoor P, Apajalahti S, Kontio R. Regeneration of cystic bone cavities and bone defects with BAG S53P4 in the upper and lower jaws. J Craniofac Surg. 2017 Jul;28(5):1197-1205. doi: 10.1097/SCS.0000000000003649. (a)

Stoor P, Suomalainen A, Mesimäki K, Kontio R. Rapid prototyped patient specific guiding implants in critical mandibular reconstruction. J Craniomaxillofac Surg. 2017 Jan;45(1):6370. doi: 10.1016/j.jcms.2016.10.021. [Epub 2016 Nov 5]. (b)

Tabatabaei Qomi R, Sheykhhasan M. Adipose-derived stromal cell in regenerative medicine: A review. World J Stem Cells. 2017 Aug 26;9(8):107-117. doi: 10.4252/wjsc.v9.i8.107.

Takahashi K, Tanabe K, Ohnuki M, Narita M, Ichisaka T, Tomoda K, et al. Induction of pluripotent stem cells from adult human fibroblasts by defined factors. Cell. 2007 Nov;131(5): 861-72. doi:10.1016/j.cell.2007.11.019.

Tirkkonen L, Halonen H, Hyttinen J, Kuokkanen H, Sievänen H, Koivisto AM, et al. The effects of vibration loading on adipose stem cell number, viability and differentiation 
towards bone-forming cells. J R Soc Interface. 2011 Dec;8(65):1736-47. doi: 10.1098/rsif.2011.0211. [Epub 2011 May 25].

Tuan RS, Boland G, Tuli R. Adult mesenchymal stem cells and cell based tissue engineering. Arthritis Res Ther. 2003;5(1):32-45. [Epub 2002 Dec 11].

Vanhatupa S, Ojansivu M, Autio R, Juntunen M, Miettinen S. Bone morphogenetic protein2 induces donor-dependent osteogenic and adipogenic differentiation in human adipose stem cells. Stem Cells Transl Med. 2015 Dec;4(12):1391-402. doi: 10.5966/sctm.2015-0042.

[Epub 2015 Oct 22].

Wang J, Feng JQ. Signaling pathways critical for tooth root formation. Review. J Dent Res. 2017 Oct;96(11):1221-1228. doi: 10.1177/0022034517717478. [Epub 2017 Jun 30].

Wang L, Detamore MS. Tissue engineering the mandibular condyle. A review. Tissue Eng. 2007 Aug;13(8):1955-71.

Wang L, Tran I, Seshareddy K, Weiss ML, Detamore MS. A comparison of human bone marrow-derived mesenchymal stem cells and human umbilical cord-derived mesenchymal stromal cells for cartilage tissue engineering. Tissue Eng Part A. 2009 Aug;15(8):2259-66. doi: 10.1089/ten.tea.2008.0393.

Wang L, Zhao L, Detamore MS. Human umbilical cord mesenchymal stromal cells in a sandwich approach for osteochondral tissue engineering. J Tissue Eng Regen Med. 2011 Oct;5(9):712-21. doi: 10.1002/term.370. [Epub 2010 Dec 30].

Wang RN, Green J, Wang Z, Deng Y, Qiao M, Peabody M, Zhang Q, Ye J, Yan Z, Denduluri S, Idowu O, Li M, Shen C, Hu A, Haydon RC, Kang R, Mok J, Lee MJ, Luu HL, Shi LL. Bone Morphogenetic Protein (BMP) signaling in development and human diseases. Genes Dis. 2014 Sep;1(1):87-105.

Warnke PH, Springer IN, Wiltfang J, Acil Y, Eufinger H, Wehmöller M, et al. Growth and transplantation of a custom vascularised bone graft in a man. Lancet. 2004 Aug 28-Sep 3;364(9436):766-70.

Weiss KR. To B(MP-2) or not to B(MP-2) or Much ado about nothing. Are Orthobiologics in Tumor Surgery Worth the Risks? Clin Cancer Res. 2015 Jul 1;21(13):2889-91. doi: 10.1158/1078-0432.CCR-14-3069. [Epub 2015 Jan 21].

Xu QL, Furuhashi A, Zhang QZ, Jiang CM, Chang TH, Le AD. Induction of salivary glandlike cells from dental follicle epithelial cells. J Dent Res. 2017 Aug;96(9):1035-1043. doi: 10.1177/0022034517711146. [Epub 2017 May 25]. 
Yang F, Miao Y, Wang Y, Zhang LM, Lin X. Electrospun zein/gelatin scaffold-enhanced cell attachment and growth of human periodontal ligament stem cells. Materials (Basel). 2017 Oct 12;10(10). pii: E1168. doi: 10.3390/ma10101168.

Yu J, Vodyanik MA, Smuga-Otto K, Antosiewicz-Bourget J, Frane JL, Tian S, et al. Induced pluripotent stem cell lines derived from human somatic cells. Science. 2007 Dec;318(5858): 1917-20. doi:10.1126/science.1151526.

Zhang Y, Madhu V, Dighe AS, Irvine Jr JN, Cui Q. Osteogenic response of human adiposederived stem cells to BMP-6, VEGF, and combined VEGF plus BMP-6 in vitro. Growth Factors. 2012 Oct;30(5):333-43. DOI: 10.3109/08977194.2012.720574

Zétola A, Ferreira FM, Larson R, Shibli JA. Recombinant human bone morphogenetic protein-2 (rhBMP-2) in the treatment of mandibular sequelae after tumor resection. Oral Maxillofac Surg. 2011 Sep;15(3):169-74. doi: 10.1007/s10006-010-0236-7. [Epub 2010 Jun 24]. 


\section{LEGENDS FOR FIGURES}

Fig 1. The classical triad of tissue engineering: cells, supporting scaffold and growth factors.

Fig 2. Current concept of tissue engineering. The cells communicate with its environment with structural, physical, chemical and cellular components which brings complexity to tissue engineering. EVs are new area of interest, with potential applicability in stem cell therapy and tissue engineering. Image from https://www.esciencecentral.org/ebooks/ebookchapter/resident-stem-cellsstimulation-new-promise-for-tissue-regeneration--165/3.

Fig 3. Stem cell hierarchy. Zygote and early cell division stages to the morula stage are defined as totipotent. At the blastocyst stage, only the cells of the inner cell mass (ICM) and the embryonic stem cells retain the capacity to build up all three primary germ layers, as well as the primordial germ cells, and are pluripotent. Stem cells in the fetal tissues exist during fetal development and some stem cells are retained until adult age. In adult tissues, multipotent stem and progenitor cells exist in tissues and organs to replace lost or injured cells. Figure downloaded from http://synentec.com/imagetypes/content_image_full/stem_cell_development_function_3.png

Fig 4. Light microscopic images showing adipose stem cells (AT-MSCs) proliferation at day 1 (A), 2 (B) and 4 (C) post isolation. Fluorescence microscope image of live/dead staining of ASCs and biomaterial, with live cells (green) and dead cells (red) depicting cell adhesion to the biomaterial and cell viability (D) and (E). (Reprint from Mesimäki et al 2009 granted by Elsevier)

Fig 5. Confirming the multipotent nature of AT-MSCs. Alkaline phosphatase staining on osteogenic differentiation cultures of AT-MSCs and biomaterial, control culture (A) and differentiation culture (B). Oil red O staining confirming adipose differentiation of AT-MSCs cultured in monolayer (C). Alcian blue staining confirming chondrogenic differentiation of AT-MSCs cultured in micro mass culture format (D). (Reprint from Mesimäki et al. 2009 granted by Elsevier)

Fig 6. Preoperative clinical status 28 months after removal of keratocyst by hemimaxillectomy (A). Final result 1 year after bone and soft tissue reconstruction, with temporary dental implant rehabilitation (B). (Reprint from Mesimäki et al 2009 granted by Elsevier)

Fig 7. Second and third operation. (A) The titanium cage filled with $3-\mathrm{TCP}$ 
and adipose stem cells, before insertion in the prepared rectus abdominis muscle pouch. (B) The bony regenerate in the rectus abdominis muscle. Skeletal scintigraphy was performed to confirm bone activity. (C) The rectus abdominis free-flap raised, muscle pouch and titanium cage opened. Note bleeding from the bone. The tissue engineered bone was clinically confirmed to be rigid. (D) Histological section of the biopsy from the tissue-engineered bone showing normal mature bone structures. (Reprint from Mesimäki et al 2009 granted by Elsevier)

Fig 8. Final reconstruction. A and B. The flap was left to epithelialize and prosthetic rehabilitation was carried out with a fixed bridge. C. Part of the titanium cage was removed to enable placement of implants. (Courtesy of Dr. Jari Mauno)

Fig 9. In the future, extracellular vesicles (EVs) secreted by stem cells could be used in tissue engineering avoiding some adverse effects in the use of stem cells. EVs could be harvested from e.g. fat tissue or blood either autologous or allogeneic, and triggered to enhance bone formation is a defect site in a similar fashion as MSCs would, thus avoiding potential adverse immune reactions. Harnessing the paracrine effects of stem- and progenitor cells without having to administer living, replicating, potentially pluripotent cell populations is an advantage in regard to safety, regulation, and complexity. 